\title{
EXTRAÇÃO DE PRÉ-MOLARES - RELATO DE CASO
}

\section{EXTRACTION OF PRE-MOLARS - CASE REPORT}

\section{Victor Raposo de Assis Martins}

Especialista em Ortodontia, Universidade Federal Fluminense, Niterói, Rio de Janeiro, Brasil

\section{Henrique da Graça Pinto}

Graduado em Odontologia, Faculdade Trabalho realizado na Faculdade de Odontologia da Universidade Federal Fluminense (UFF - Niterói - RJ)
Autor de Correspondência:

Victor Raposo de Assis Martins

Rua Otávio Carneiro n 85 apto 1004-

Icaraí - Niterói - RJ

CEP. 24220-215

Tel. (21) 988200290

Email: victorraposo77@yahoo.com.br

Trabalho realizado na Faculdade de Odontologia da Universidade Federal Fluminense (UFF - Niterói - RJ)

\section{RESUMO}

Em determinados casos na área da ortodontia é preciso indicar os procedimentos de extração para que se consiga um bom resultado clínico no final do tratamento. $\mathrm{O}$ objetivo do presente trabalho é relatar um caso clínico onde o paciente possuía maloclusão classe I de Angle com biprotrusão que teve como parte do tratamento a extração de 4 pré-molares (dentes 14,24,34,44) e mostrar os ótimos resultados com tais procedimentos. $\mathrm{O}$ tratamento teve a duração de 4 anos, com um resultado e estabilidade bastante satisfatórios.

Descritores: extrações, ortodontia, pré-molares 


\begin{abstract}
In certain cases in the area of orthodontics it is necessary to indicate the extraction procedures in order to obtain a good clinical result at the end of the treatment. The objective of the present study was to report a clinical case where the patient had Angle class I malocclusion with biprotrusion that had as part of the treatment the extraction of 4 premolars (teeth 14,24,34,44) and show the excellent results with procedures. The treatment lasted 4 years, with a satisfactory result and stability.
\end{abstract}

Keywords: extractions, orthodontics, premolars

\title{
INTRODUÇÃO
}

A busca ao tratamento ortodôntico visando uma melhora na estética facial é um fato bastante frequente entre os pacientes que procuram os ortodontistas. A literatura mostra que a Ortodontia, através da melhora do posicionamento dos dentes anteriores, pode levar a alterações benéficas no perfil tegumentar quando há um correto diagnóstico e plano de tratamento. Portanto, a avaliação dos tecidos moles é um fator fundamental na elaboração do planejamento ortodôntico, visando atender essas expectativas do paciente. Na história da Ortodontia, durante anos, não se admitia o planejamento com extrações, pois se acreditava que mecânicas expansionistas poderiam estimular no aumento das bases ósseas. Mais tarde, com o advento dos raios-X e do cefalostato, começaram os estudos relacionando as estruturas dentárias, ósseas e tegumentares

(ANGLE, 1907).

Alguns autores relataram alterações no perfil mole nos pacientes submetidos a tratamento ortodôntico com extração de primeiros pré-molares e retração dos dentes anteriores (BASCIFTCI et al., 2003).

Dentre as maloclusões existentes, a literatura mostra que a Classe I de Angle é a mais prevalente. O apinhamento e/ou protrusão dentária estão entre as queixas mais comuns dos pacientes que buscam o tratamento ortodôntico. Muitos desses casos são tratados com extrações de dentes permanentes para se obter bons resultados. É importante destacar que o tratamento ortodôntico com extração de quatro pré-molares, quando indicado, é consagrado na Ortodontia (CAPLAN et al.,1997).

\section{APRESENTAÇÃO DO CASO}

O paciente se apresentou para o exame inicial aos 15 anos (figura . 1), com bom estado geral de saúde. Sua história médica e odontológica não possuía registros significativos. Não era portadora de posicionamento lingual anormal durante os movimentos funcionais de deglutição ou fonação. Sua queixa principal eram os dentes tortos. Quanto ao aspecto dentário, era portadora de uma má oclusão Classe I de Angle, sobremordida de $4 \mathrm{~mm}$ sobressaliência de $6 \mathrm{~mm}$, linha média inferior desviada $2 \mathrm{~mm}$ para esquerda. 
COPYRIGHT @ 2018 INTERNATIONAL JOURNAL OF SCIENCE DENTISTRY | AVAILABLE ONLINE http://www.periodicos.uff.br/index

Discrepância do perímetro do arco inferior de $-6 \mathrm{~mm}$ e grande inclinação vestibular dos incisivos inferiores. Por conta da inclinação dos incisivos e da falta de espaço nos arcos foi feito o plano de tratamento que constava no uso do tratamento ortodôntico com a extração dos 4 primeiros pré-molares (figura . 2- final do tratamento).
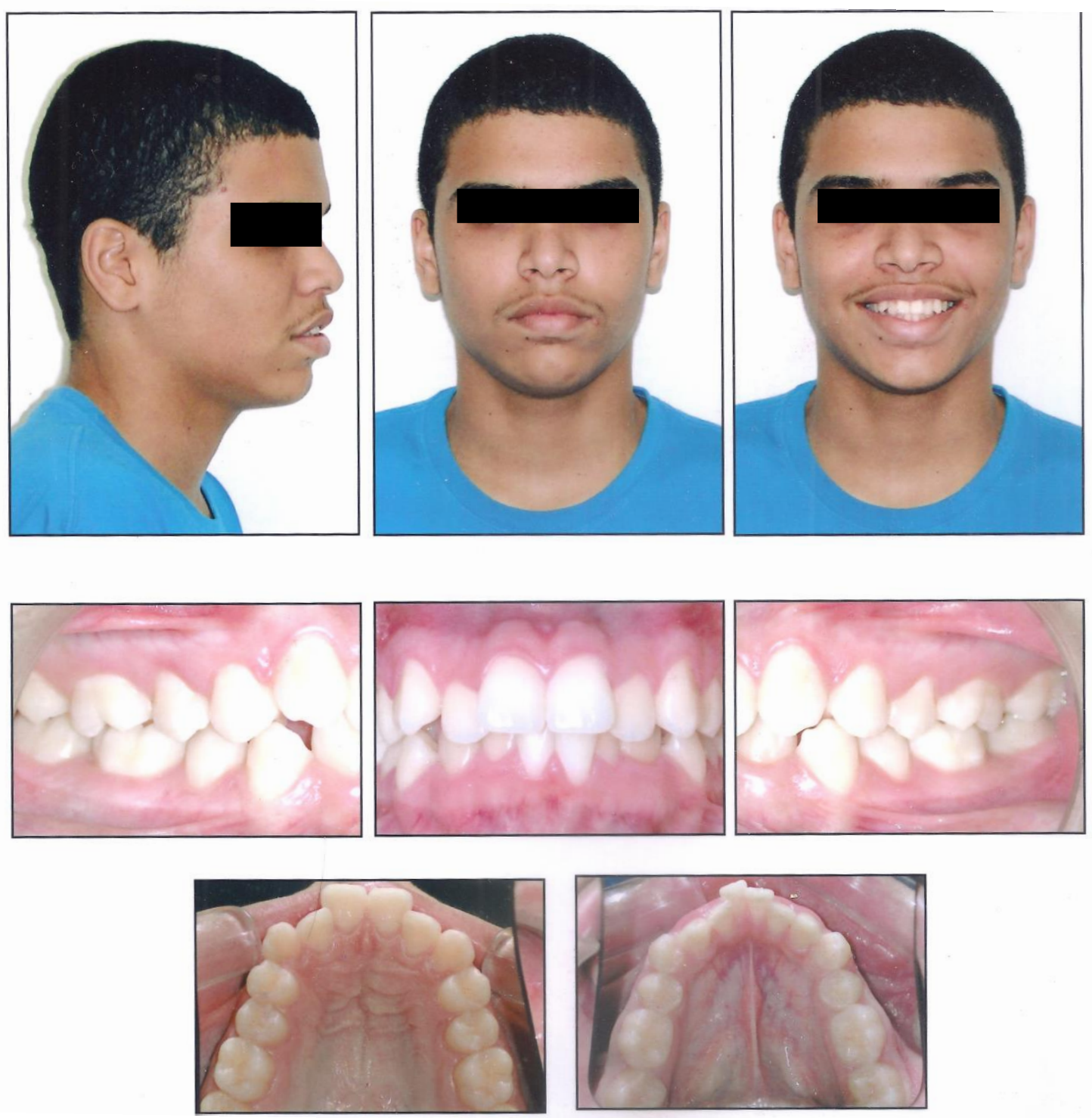

Figura 1 ( fotos iniciais) 

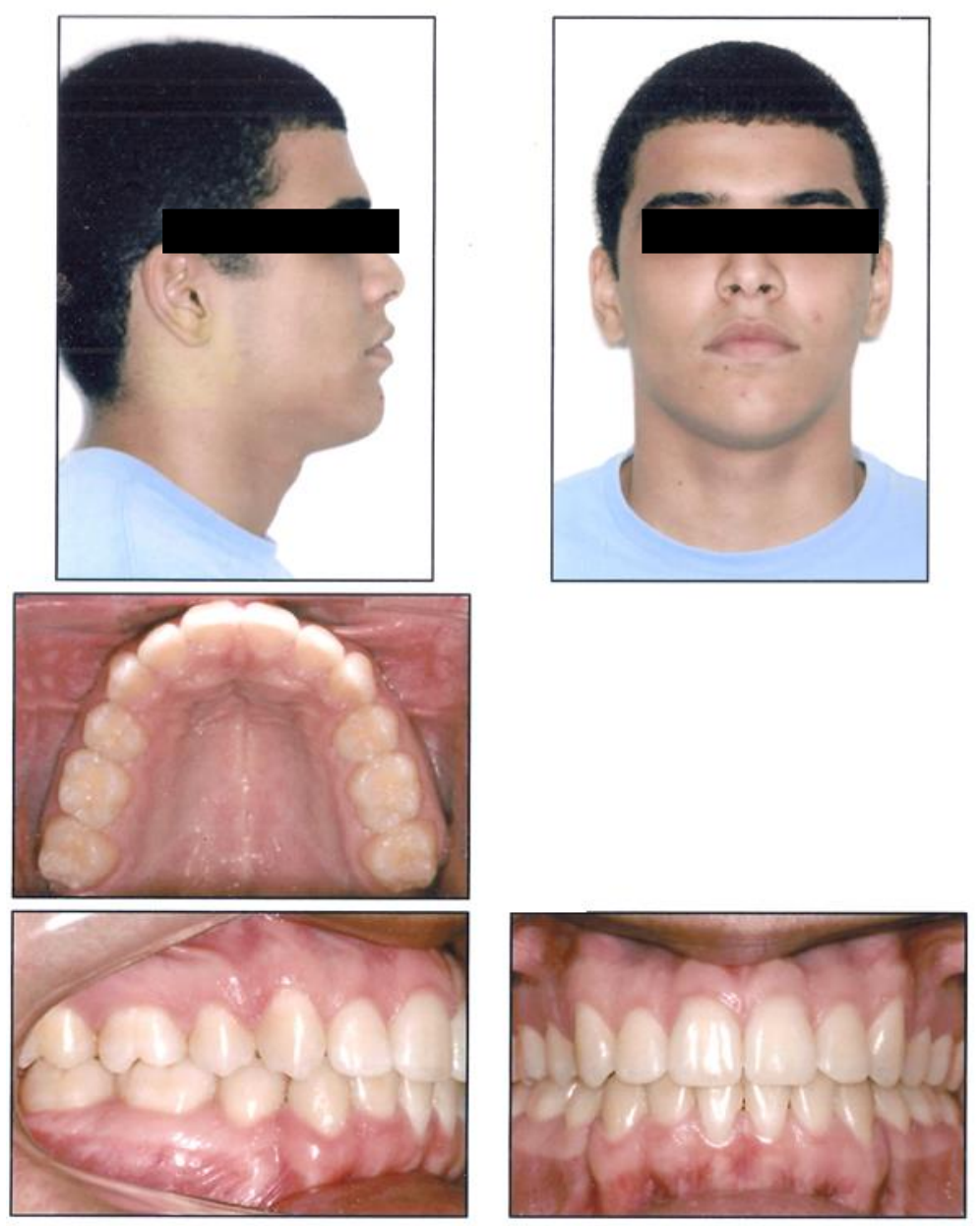

Figura. 2 (4 anos depois)
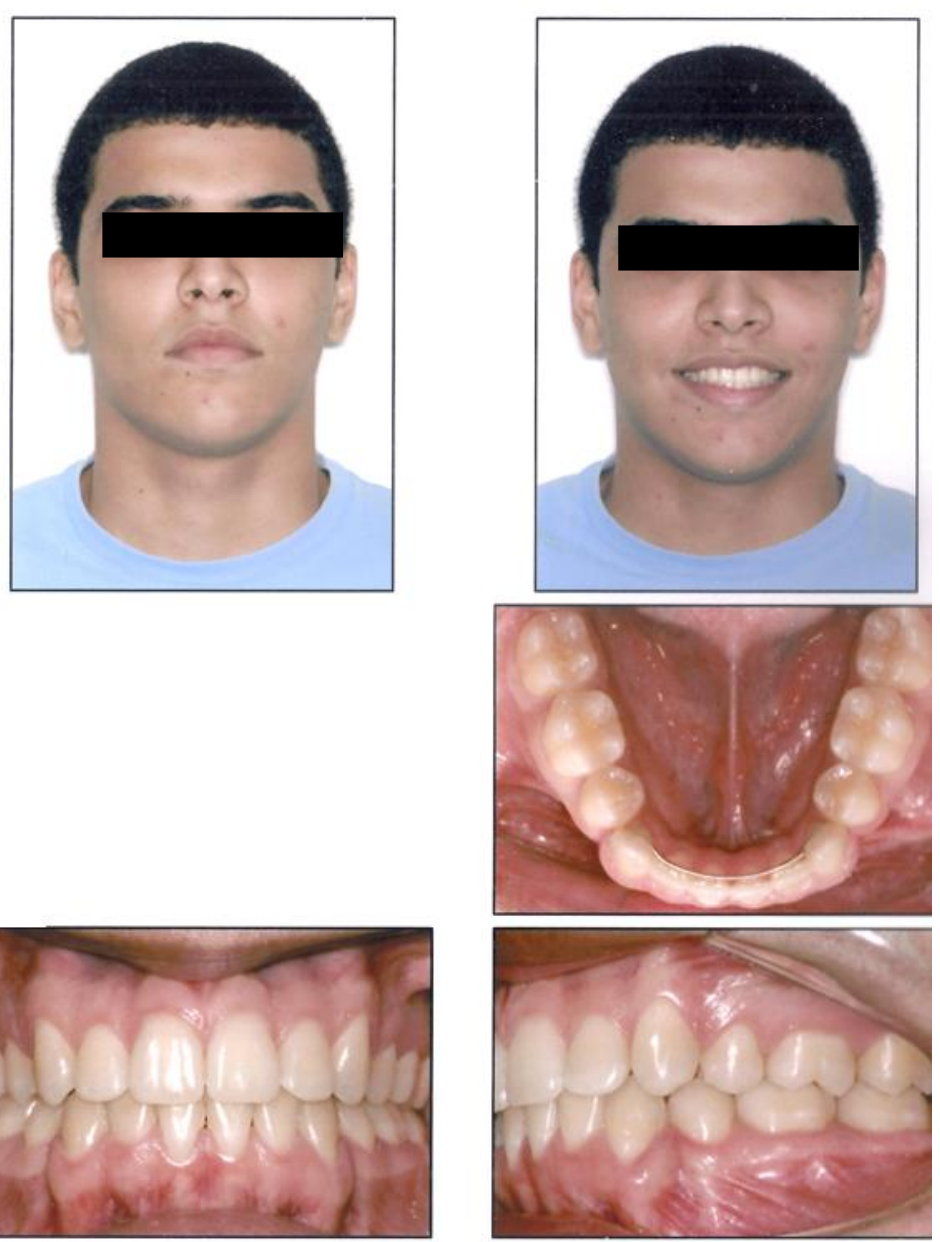

\section{DISCUSSÃO}

A discrepância de modelo deve ser avaliada tanto na arcada superior quanto na inferior. Mas, para fins de diagnóstico, a arcada inferior é prioridade, devido à maior dificuldade em se obter espaço. Quando o ortodontista se depara com uma discrepância de modelo (DM) negativa acentuada na arcada inferior, dificilmente consegue tratar o paciente sem extrações dentárias. Para pequenas discrepâncias negativas, em grande parte dos casos, o tratamento é realizado sem extrações. Assim, o espaço pode ser obtido por aproveitamento do leeway space (quando ainda for possível), stripping, correção de inclinações acentuadas para mesial dos dentes posteriores inferiores e pequenas expansões e/ou projeções com objetivo de restabelecer inclinações normais aos dentes inferiores, principalmente se acompanhadas por disjunção maxilar (LIMA et al., 2001).

Nas discrepâncias de modelo nulas ou positivas, o tratamento é realizado sem extrações, a não ser que o paciente apresente outro problema associado que as indique.

Em situações de acentuada inclinação vestibular dos incisivos, evidenciando-se grande discrepância cefalométrica (DC) e expressiva convexidade facial, muitas vezes 
são necessárias extrações para reposicioná-los, refletindo positivamente no perfil do paciente. A tendência atual do diagnóstico ortodôntico é de valorizar mais as características faciais e se prender menos aos valores cefalométricos (OLIVERIRA et al., 2008).

Assim, algumas vezes, finaliza-se um caso com incisivos projetados em função de não alterar um perfil satisfatório, podendo-se lançar mão de desgastes interproximais (stripping) para criar espaços que possibilitem uma pequena verticalização desses dentes. Nem sempre acontecem as alterações de perfil esperadas durante o tratamento ortodôntico.

\section{CONCLUSÕES}

O tratamento ortodôntico da maloclusão de classe I de Angle com biprotrusão e falta de espaço tem uma ótima indicação para extração de 4 pré-molares, sendo um tratamento geralmente com ótimos resultados tanto funcionais quanto estéticos e com alta estabilidade dos resultados.

\section{REFERÊNCIAS}

1. ANGLE, E. H. Malocclusion of the Teeth. 7. ed. Philadelfia: SS White Dental, 1907. $628 \mathrm{p}$.

2. BASCIFTCI, F. A.; USUMEZ, S. Effects of Extraction and Nonextraction Treatment on Class I and Class II Subjects. Angle Orthod., Appleton, v. 73, n. 1, p. 36-42, Jan. 2003.

3. CAPLAN, M. J.; SHIVAPUJA, P. K. The Effect of Premolars Extraction on the Soft Tissue Profile in Adult African-American Females. Angle Orthod., Appleton, v. 67, n. 2, p. 129-136, Apr. 1997.

4. LIMA, C. E. O.; RINO, W.; TAKAHASHI, T.; CARVALHO, S. M. R.; LIMA, M. T. O. Perfil Facial: Alterações Cefalométricas em Casos Tratados com Extrações de Pré-Molares e Mecânica de Forças Direcionais. R. Dental Press Ortodon. Ortop. Facial, Maringá, v.6, n. 3, p. 37-46, maio/jun. 2001.

5. OLIVERIRA, G. F.; ALMEIDA, M. R.; ALMEIDA, R. R.; RAMOS, A. L. Alterações Dentoesqueléticas e do Perfil Facial em Pacientes Tratados Ortodonticamente com Extração de Quatro Primeiros Pré-Molares. R. Dental Press Ortodon. Ortop. Facial, Maringá, v.13, n. 2, p.105-114, mar./abr. 2008. 